\title{
EXPLORING STUDENTS' REFLECTIVE NARRATIVES ON LANGUAGE AS THE SUBJECT OF THEIR STUDIES
}

\author{
Loreta Chodzkienè \\ Institute of Foreign Languages, Faculty of Philology, Vilnius University (Lithuania)
}

\begin{abstract}
The present research lies within the realms of autobiographical self-reflection extending and developing students' skills of critical thinking on language as the subject of their studies. The importance of looking back over different stages of the learning process and identifying the cases of success and failure in one's life experience has been emphasized by many scholars, among them, Mason (1994), Moon (1999), and Bold (2012). The paper focuses on the data obtained from the semi-structured reflective essays entitled "My Language Learning Autobiography" written by 250 students of the study programme "English and another foreign (Russian, French, Spanish, Norwegian) language" taught at the Faculty of Philology, Vilnius University, during the period of 2015-2018. With more than fifteen years of foreign language(s) learning experience at school and university, the target students have demonstrated their capacity to mediate over the concept of language, discuss the necessity of the knowledge of foreign languages in the contemporary world, assess themselves as language learners and contemplate on the ways, how foreign language(s) should be taught/learnt. The research period of four years allowed us to identify an interesting fact related to the students' attitudes towards a relatively diminishing role of a language teacher. The chosen medium happened to be supportive in examining the students' personal actions as well as self-motivating.
\end{abstract}

Keywords: Narrative, self-reflection, foreign language, learning experience.

\section{Introduction}

The designers of the twenty-first century pedagogy have been constantly amending the list of competences necessary for the contemporary learners, smart millennials, enjoying the advantages of globalization as well as rapid progress in technology (Whitby, 2007). The priority is given to the development of metacognitive skills: as "metacognition reflects an individual's critical awareness of how they think and learn, and their assessment of themselves as a thinker and learner." (Scott, 2015, p. 10). Scott acknowledges that metacognition can be developed by encouraging learners to contemplate on the ways towards achievements or failures through integration of reflection which identifies their confusion and acknowledges difficulties. The latter insight reiterates Whitby's opinion on effective pedagogies based on a thorough understanding of how people learn.

By unpacking the meaning of reflection one can learn its several interpretations. This research paper refers to the definition of the term provided by Bolton (2010, p, xix), who describes reflection as an "in-depth consideration of events or situations: the people involved, what they experienced, and how they felt about it. This involves reviewing and reliving the experience to bring it into focus, and replaying from diverse points of view." Such a rendering coincides with Moon's insights about reflection as a key mental process to be intertwined with thinking and learning (1999, p. 10) through mediation over one's own abilities, critical analysis and deeper examination of one's own actions (as cited in Alexandrache, 2014, p.21). It correlates with Dewey's ideas relating reflection to active, persistent, and careful consideration of any belief or supposed form of knowledge in light of the grounds that support it and the further conclusions to which it tends. (1933, p. 9)

A learner's competence of being reflexive enters into several explanations, such as: "to be able to stay with personal uncertainty, critically informed curiosity and flexibility to find ways of changing deeply." (Bolton, 2010). Williams, Woolliams and Spiro $(2012$, p. 2) distinguish five compounds of the target competence: first, they emphasize a person's openness to different ideas, ability to see things from different angles. Second, they value one's curiosity as an ability to ask questions. Third, they stress one's patience when the cases are difficult or problematic. Fourth, they identify the importance of being honest with oneself, one's uncertainties about what wrong or right is - and one's writing needs to make this transparent to others. Finally, they mention the skill of rigorousness, which carries the meaning of being analytical and acting on the gained insights.

The development of the discussed competence components requires a thorough consideration of methodological approaches where the function of a reflective narrative becomes pivotal. Bold depicts narrative as "a means of developing and nurturing the skills of critical reflection and reflexivity" (2012, p. 2). To be more precise, writing in autobiographical style cast a learner in a researcher's role where the focus shifts towards the learner's inner world, his/her 'self' and relationship with the surrounding context. 
The $1^{\text {st }}$ person writings (memoirs, autobiographies, diaries) are described as tools of self-construction: they are not just accounts of what happened but "ways of moulding the stuff of the past into the models of what the writers wish to be: writing an account of one's life is an act of self-creation" (Heehs, 2013, p. 6). Reflective narratives found application in diverse human activities (nursing, teaching, counselling, travelling, etc.) for many purposes. Recently, Language Learning Autobiography as well as the Autobiography of Intercultural Encounters as a method of critical reflection has stepped in the fields of language teaching-learning or cultural discoveries (Byram \& et.al). The projects by the European Council and European Commission, e.g., LLP Grundwig: Learning Partnership "PLURI-LA" (2012-1-FR1-GRU06-356503), NordPlus "DELA NOBA" (NPHZ-2013/10022) encouraged the idea of eliciting language learners' struggles and joys when in contact with new languages and cultures.

The beginning of this research also dates back to "DELA NOBA" project run in the period 2013-2015 and promoted Language Learning Autobiography as a tool to recognise language learning being inseparable from the learners' emotions and embodied experience. This practice has been continued up to recent days, and the current collected data allows language teachers to analyse the students' attitudes towards their encounters with foreign language learning from different perspectives.

The aim of this paper is to analyse the students' attitudes towards current foreign language teaching and learning process described in their narratives, entitled Language Learning Autobiographies. To accomplish the aim for this particular paper the following objectives were set:

- to identify the students' interpretations of the concept of language;

- to cast light on language learners' self-assessment;

- to detect the ways how languages should be taught from the students' perspectives;

- to distinguish the roles of a language teacher of the 21 st century.

\section{Context \& methodology (and data characteristics)}

The assignment on the reflective narrative 'My Language Learning Autobiography' has been an integral part of the course on 'Intercultural Communication', offered to the students of the study programme "English and another foreign (Russian, French, Spanish, Norwegian) language". The programme is run at the Institute of Foreign Languages, Faculty of Philology, Vilnius University. Given the fact that the target languages belong to different language families, students face an opportunity to analyse them as systems from numerous linguistic perspectives. After completion of a substantial number of subjects, in the $3^{\text {rd }}$ year, they join the course on Intercultural Communication, which aims at demonstrating language as an integral part of the human cognition and lays emphasis on language and culture relationship, peculiarities of verbal/non-verbal communication, communication styles, identity issues, etc.. Students are encouraged to reflect upon their personal intercultural encounters or cultural misunderstandings they have come upon, and discuss the ways they managed to deal with them. Since reflection as an approach of learning is applied to a number of tasks of the course, students get aware of the particular writing style that enables them to disclose their personal pathways towards many discoveries, including the way towards foreign language proficiency.

To address the objectives of the research the students are asked reflect upon the four issues, such as the concept of language per se, favoured foreign language teaching methods, teachers' roles, and their as language learners' strengths and weaknesses. Consequently, the raised issues became the guiding pillars for their reflections and presented a semi-structure to their narratives.

For the analysis, the texts of 250 reflective narratives, written during the period of 2015-2018, ranging from 800 to 1200 words, were selected. Each narrative was numbered and labelled according to the second foreign language of students' studies. Each author of the narrative gained an informant's status. Distribution of the sample group by the languages they study fell in the following proportions: 90 students of English and Spanish, 70 students of English and French, 50 students of English and Russian, 50 students of English and Norwegian, respectively.

The analysis of the narrative texts was based on qualitative content analysis (Bitinas et al., 2008) which assisted in navigation through the abundancy of data presented by the informants. Due to limited number of pages for this paper the following parts will present a summary of the informants' reflections.

\section{Review of the current foreign language teaching and learning process in Lithuania: students' perspective}

Prior to the analysis of the reflective narratives, it should be mentioned that English, as the first foreign language, is taught in primary schools of the Republic of Lithuania since the $2^{\text {nd }}$ year. The majority of the target students have been in contact with this language for longer than fifteen years. While their exposure to the second foreign language (Spanish, French, Russian and Norwegian) has been lasting just for a third year. Therefore, while exploring the informants' narrative puzzles, there has been much more evidence found on their encounters with the first foreign language, i.e., English, rather than the second one, Spanish, French, Russian or Norwegian. 


\subsection{Who am I, a language learner?}

The target students were 'born and grew up in independent Lithuania' (ES1). The years of their birth coincided with the period of information technologies to start stepping over the thresholds of their homes, when: 'families were getting computers, which meant interface with English' (ESN6). 'An unlimited, albeit slow, access to the internet, opened a new era in activities,- computer games, news programmes, message boards - all of them were explored with the aid of English, the lingua franca of the Internet.' (SP17). Further advances in ICT are described as magic tools for language learning: 'cable television kept me exposed to Cartoon Network since the age of three. As a child I was enamoured with it, spending worrying amounts of time watching TV and learning English quite organically' (FR6). 'The wonders of digital technology, most importantly video games, gave me a considerable amount of knowledge, which now has been taken over as the language of my thoughts' (FR63).

Naturally, 'English has become so ingrained in their [L.Ch.] brain via continuous exposure to the world wide web' (EN5) that consequently, its proficiency levelled off with their native languages. Furthermore, some parents' intention to start their children learning foreign languages at an early age resulted in attending extracurricular English activities ( 30 per cent of the informants): 'it was the parents who saw the value of languages and encouraged me to learn English at an early age" (ES29). Due to the evidence given, some learners enrolled and still enrol in primary schools with a certain background of English, while others, at the same time, start learning it from scratch. A class of children with diverse language proficiency envisages complications at the very beginning of the teaching and learning process: it requires teachers' professional commitment on application of individualized teaching strategies, which is a rare practice in primary schools, and, in many cases, leads towards dissatisfaction of both sides.

Despite initial discrepancies, the majority of the informants acknowledge language learning as 'an extremely difficult' (RU2) and 'time consuming process, requiring much effort and dedication' (ES22), demanding one's 'perseverance' (NOR4), 'responsibility for completion the given tasks' (ES14) and 'self-discipline' (ES9). Among the personal character features listed to meet the demands of a 'diligent learner' (ES53), the informants stress the importance of one's 'open mindedness' (FR43), the ability to 'maintain the quality of performance' (FR15), to have 'a desire to excel peers' (FR17) and hunger 'for international experiences to unveil thoughts of other people' (ES19). Above all, 'never daring to give up' (NOR6) is acknowledged by the language students as a driving force towards success.

Mirroring the informants' reflections on their personal weaknesses or negative emotions towards language learning, 'impatience', 'laziness' and 'boredom' prevail in many narratives. The latter emotional state happen to be typical of the millennials grown up in the digital world. Their own or groupmates' inability to produce a correct answer instantly 'drive them crazy' (NR36) urging to escape from the classroom. In contrast to 'perfectionists', those, who are shy, feel embarrassed and psychologically insecure to speak in front of their demanding groupmates, face 'a constant nerve-wracking challenge of not to make a mistake or not to mix up a word' (ES6). 'The fear of being laughed at' (FR47) prevents nearly half of the informants from being active and productive in the classroom: 'I prefer keeping silent to speaking' (RU2). Alongside with the fear of speaking and active participation, poor skills of time management 'due to external distractors' (NOR42) and 'poor concentration skills' (ES76) were acknowledged as the most typical weaknesses of the contemporary foreign language learners.

Putting all the negative aspects aside, the majority of the informants do not limit themselves to the two languages of their studies; they indicate their determination to prolong the list of their foreign languages up to six or seven as a distinctive feature of one's personality development as well as a success factor towards the future career ladder.

\subsection{What is language for me, a language learner?}

The answers to this question generated quite a large amount of the students' surprise, as exposure to languages for more than fifteen years never has made them consider such an issue. Their interpretations on the concept of language are vivid, though diverse, therefore, can fall into several interpretation lines.

The informants' relationship with English and another foreign language allows them to compare and contrast at least two different linguistic systems at the same time, which, consequently, leads to the perception of language 'as a living organism that constantly changes' (FR32). Therefore, language learning is acknowledged as 'a lifelong process that needs updating every time' (RU15). References to the contemporary dictionaries allow them to describe language as 'a system of arbitrary and conventional signs', 'a tool of communication' (112 informants). Further to it, language is reflected upon as 'an everyday component that unites people' (FR59), that 'identifies one's communication style' (23 informants) and 'depicts one's attitudes towards different life aspects' (ES11). Language indicates the 'importance of one's social status' (ES34) and 'different ways of thinking' (22 informants). However, language is more than the definitions in the living dictionaries, language should be seen as a 'complicated organic system that lives and dies along with its people' (FR11) or as 'a drop in the language ocean allowing us to see how many languages there are in the world, and spot out Lithuanian among them' (FR52). 
Creative minds of the language students reflect upon the presence of language as 'lens to another culture' (13 informants), 'window to another world' (RU11): "Language permits to distinguish one group of people from another, but it brings the same community together' (RU37). Language is seen as 'a core of society making its people together' (ES88), 'the glue that keeps society working' (FR17), on the other hand, 'a provider of the meaning and security' (FR28).

From students' personal perspectives language is considered to be 'the best gift given to a person' (7 informants), 'the feature that distinguishes us, humans, from the world of mammals' (NOR33), or 'a human property: the more languages you know, the more human you are' (Masaryk quoted by RU39). Language is described as: 'a means of self-expression' (3 informants), 'a sign of one's identity' (19 informants), 'one's personal domain reflecting a person's style and character' (NOR25), or 'a criterion of one's education' (NOR18) - "the limits of your language are the limits of your world' (Wittgenstein quoted by RU11). The studies of several languages at the same time allow students to feel the shifts in their personalities: 'My whole body responds to a language that I'm speaking at that moment' (FR18) because "learning two languages makes you switch from one language to another, and consequently, feel your inner self changing: the way you think and express yourself' (ES24).

Despite the majority of resourceful interpretations of the language concept intertwined with quotations by prominent authors or extracts taken from the folk wisdom, there also appeared some cases demonstrating the informants' official indifference towards the subject of their studies, as they have 'never thought too much of what language is. Probably, a set of words?' (RU19). The latter idea leads to an assumption, that every study programme has some students who are still in search for their inner selves; and their personal uncertainty about the subject of their studies, first, reduces the level of their motivation and, second, becomes contagious to the others sharing with them the same environment.

\subsection{What do I expect of a language teacher?}

Given the fact that 'language is highly linked with communication', it is the teacher who is expected to be 'communicative and willing to establish relationship with students'. The latter teacher's feature was identified as the most important character trait as well as qualification attributed to the image of a good teacher. Further to it, a good teacher is required to be:

- a charismatic, warm and helpful personality: 'making students feel at home in the classroom' (RU17); 'creating an appropriate learning environment with no tension at all' (ES66);

- a role model professional, passionate about his/her subject, inspiring students to love the subject of their studies: 'promoting the usefulness of every language' (ES22);

- systematic: 'being able to provide the whole language system rather than concentrating on separate themes' (NOR4) or 'picking up topics randomly' (RU27); 'focusing on knowledge transfer rather than assessment' (FR56);

- encouraging and motivating: 'preventing students from the fear of their mistakes' (RU3) as well as the dread of public speaking;

inventive when designing classroom activities; individualizing the study process by choosing the most suitable learning strategies according to the learner types: 'arousing natural curiosity to learn something more that would step over the boundaries of a mere home task' (RU11),

- selective: 'in choosing tasks for language learners' as well as teaching materials which should be 'relevant to students' life, not boring' (20 informants);

- emphatic: 'dealing with students' mistakes in a nice manner' (ES16);

(RU21);

- strict (though not too much) - 'strong enough to ignore students' complaints and excuses'

- facilitating the whole learning process, though, escaping dominance: 'teachers should be the guides who want to show the beauty of the language, all the opportunities that language can offer, and to convey their knowledge in the best manner they can" (FR20);

- constantly improving themselves: 'unfortunately, not many teachers understand that the awarded diploma in not the top in their career ladder.'(ES66).

Nearly 90 per cent of the informants strongly believe that foreign languages should be taught by the native speakers, as "their remarks and pieces of advice appear more credible" (FR19). There was some uncertainty about the necessity of the physical presence of a language teacher in general, "when there are so many means around you' (NOR44), however, this discussion leads towards the last part of the paper on foreign language teaching-learning methods.

\subsection{How should languages be taught?}

Learners' exposure to a foreign language over fifteen years, although passed through pains and gains, undoubtedly, has broadened their experience in how languages are or should be taught. Bearing in mind the fact that language learning is highly dependent on every student's learning style and personality, the informants admit that everyday practicing is compulsory and within the scope of their responsibility.

The learners' feedback of teaching methods present a number of ideas that could be generalized in the following way. First, at school, foreign language learners are facing a constant change of teachers and delivery of the targeted themes in 'dribs and drabs'. Only the approaching examination does bring 
some system in the study process as well as psychological security for the learners. Second, every new teacher brings a set of new methods, which make the learners 'leave their [L. Ch.] comfort zones' (NOR46) and 'become more adaptable' (RU9). Third, the prevailing tendency to avoid using the native language in the lessons of a foreign language rather than applying some translation activities to 'help us feel each language' (FR9), 'disclose structural differences and similarities of both languages' (FR28), 'unveil the impact of the native language' leaves the majority struggling with a number of unanswered questions, probably, for good. In some cases, the problems are solved with the assistance of a private teacher or a foreigner's consultancy. Therefore, the informants' longing for some learner-friendly environment has been voiced out in many narratives: a need for relaxing atmosphere full of interactive activities, friendly teacher's guidance where there is no room for doubt.

Visiting the country whose language is studied could be another way of gaining language proficiency: 'living abroad erases limitations of your vocabulary' (89 informants). This idea can be implemented with the help of Erasmus + programme, temporal jobs in foreign countries, since 'travelling and exploring the country's culture' (57 informants) or 'Work and Travel USA' programme (180 informants) are described as the best ways 'to examine one's level of language proficiency' (34 informants).

The revision of the last year (2018) narratives gives us a hint that the role of a language teacher is diminishing. One third of the informants think that learning with the help of IT provides 'live communication', which is much more beneficial than 'teacher's old-fashioned manner of teaching from a text-book' (FR7). They maintain they 'can use some apps, watch movies, listen to songs and sing themselves, Skype to your friends abroad, play games, refer to social media, or at least, take up an online course' (52 informants). This particular group neglects the physical presence of a teacher and takes the burden of learning difficulties on their own shoulders. Their opponents claim, that interactive lessons at least remind them how to communicate, otherwise, 'when glued to the screens of their iPhones' (ES61) they will finally forget about the natural manner of human communication.

\section{Concluding remarks}

The application of reflective narratives to foreign language teaching and learning turned out to be one of the most successful means in language education when its manifestation was evident in the following spheres:

- $\quad$ students' collected data provided interesting material to be analysed from different perspectives;

- students' positive attitude towards the method of introspection resulted in their sincere disclosure

of themselves, as language learners, as well as other agents involved in foreign language teaching-learning process, and the methods applied to it. Bearing in mind the positive and negative sides of the feedback, there is invaluable information for the teachers to reconsider.

Reflective narratives as a method could be highly recommended to any subject teacher for self-analysis of his/her relationship with the subject, target students and the subject per se.

\section{References}

Alexandrache, C. (2014). Journal Reflexive, an Instrument for Student Preparation in the Teaching Profession. Procedia - Social and Behavioral Sciences 149. Retrieved 11 January, 2019, from: https://www.researchgate.net/publication/266562941_Journal_Reflexive_an_Instrument_for_Stude nt_Preparation_in_the_Teaching_Profession

Bitinas, B., Rupšienè, L., \& Žydžiūnaitè, V. (2008). Kokybiniu tyrimu metodologija. Vilnius: Socialinių mokslų kolegija.

Bolton, G. (2010). Reflective Practice: Writing \& Professional Development. London: SAGE Publications Ltd.

Dewey, J. (1933). How We Think: A Restatement of Reflective Thinking to the Educative Process. Boston, MA: D.C. Health \& Co Publishers.

Heehs, P. (2013). Writing the Self: Diaries, Memoirs and the History of the Self. London: Bloomsbury.

Moon, A. J. (1999). Reflection in Learning and Professional Development: Theory and Practice. NY: Kogan Page Limited.

Scott, S. L. (2015). The Futures of Learning 3: What Kind of Pedagogies for the $21^{\text {st }}$ Century? Education Research and Foresight. Working Papers. UNESDOC. Retrieved March 16, 2019, from: https://unesdoc.unesco.org/ark:/48223/pf0000243126

Whitby, G. B. (2007). Pedagogies for the $21^{\text {st }}$ Century: Having the courage to see freshly. ACEL 2007 International Conference, Sydney, Australia. Retrieved 12 February, 2019, from: https://robertsonss.eq.edu.au/Supportandresources/Formsanddocuments/Documents/pedagogy-forthe-21st-century.pdf

Williams, K., Woolliams, M., \& Spiro, J. (2012). Reflective Writing. Basingstoke: Palgrave Macmillan. Williams, K. (2014) Getting Critical. ( $2^{\text {nd }}$ ed.). Basingstoke: Palgrave Macmillan. 